\title{
FACTORS UNDERLYING THE CONCEPT OF RISK ACCEPTANCE IN THE CONTEXT OF FLOOD-PRONE LAND USE
}

\author{
L. ALTARAWNEH, J. MACKEE \& T. GAJENDRAN \\ School of Architecture and Built Environment, University of Newcastle, Australia.
}

\begin{abstract}
The determination of acceptable risk levels for planning purposes is critical for policymakers concerned with floodplain management and safety issues; including the formulation of flood-prone land use policy and risk communication strategies. However, the concept of flood risk acceptance remains vague and is not yet fully understood in terms of how it is conceived and rationalised by the individuals engaged in flood-prone land use and development. In general terms, risk acceptance involves a complex weighing up of a range of influential factors that have evolved based on three key models: revealed preferences, expressed preferences and implied preferences. By investigating these models within the broader theoretical context of flood risk-related research, this paper, in essence, categorises six typologies that describe individuals' psychophysical/cognitive states when they face the risk, respond to it and determine its acceptability contextualised within the process of flood-prone land use change. The paper then focuses on identifying the key barriers influencing the adoption of an informed, consultative approach to acceptable flood risk assessment and governance.

Keywords: barriers, consultative approach, factors, flood-prone land use change, individuals, residential satisfaction, risk acceptance, risk perception..
\end{abstract}

\section{INTRODUCTION}

Within the scope of both sustainable development and disaster resiliency, the power of land use planning in mitigating risks from natural hazards (including flooding hazards) while promoting a better quality of life for vulnerable communities is well documented [1-4]. For urban development in flood-prone areas to continue in a resilient way, a level of flood risk must be defined as acceptable for planning purposes by all relevant parties, such as risk regulators, local planners, developers, insurers, investors and residents [5]. In general terms, risk acceptance is the concept that underlies judgement of safety [6]. It has generally been a feature examined within a wider framework of risk perception research [7]. Research within the broader context of flood hazard management has tended to concentrate on how flood-prone land users (residential and commercial occupants, and relevant stakeholders) evaluate and perceive location-related risks and benefits, and what socio-economic and demographic circumcentres make them vulnerable to flood hazards [5, 8-14]. There is a good understanding of why people continue to locate to flood-affected environments, and how they adapt to and perceive floods and flood-prone land use policy [15-20].

Nevertheless, the concept of flood risk acceptance remains vague and not fully understood in terms of how it is conceived and rationalised by vulnerable communities and individuals in the context of flood-prone land use. Few studies have been carried out [5, 14, 21-24], and 
these have focused either on the relationship between flood risk and its socio-economic and engineering factors, or between flood risk and other risks in a multi-risk context [13]. The relationship with all relevant factors has to be now rightfully constituted and examined from the viewpoints of individuals seeking a residential location, engaged in land development and construction activity, and charged with forming and implementing public flood control policies at various levels of government. This purpose of this paper emerges from this need: to provide a distinct conceptualisation for the determinant factors of flood risk acceptance from the viewpoint of individuals in the context of flood-prone land use.

The remainder of this paper is structured as follows: the next section is devoted to a fuller review of factors underlying the concept of risk acceptance in life, from the viewpoint of individuals, and then a fuller discussion of these factors is made in the realm of flood risk. Finally, the paper concludes with an outline of some barriers influencing the adoption of an informed, consultative approach to acceptable flood risk assessment and governance.

\section{RISK ACCEPTANCE: THE HOLISTIC CONCEPT}

Determining what level of risk is acceptable to individuals is not straightforward. It is a relative matter, in essence, as each individual holds a unique view towards the environment they choose to occupy, with its location-related risks [25-27]. The small body of research that has attempted to examine this concept, has shown that the determination of risk acceptance involves a complex weighing up of multifarious factors that have evolved based on three key models: revealed preferences, expressed preferences and implied preferences

First, in answering the question of 'How safe is safe enough?', Starr [28] applies a specific version of the Actor Rational Paradigm to develop what is labelled as a revealed preference model. This model characterises risk acceptance based on the assumption that, by trial and error, society has arrived at an 'essentially optimum' or 'satisfactory' outcome in which the benefits outweigh the potential risks. It considers both risks and benefits in deducing a decision rule. By applying this model to examine the relationship between risk of death and economic benefit for a number of common technologies, Starr concludes that 'the acceptability of risk appears to be crudely proportional to the third power of the benefits (real or imagined)' and that 'the public is willing to accept 'voluntary' risks roughly 1000 times greater than 'involuntary' risks.

As a consequence of the critiques around the validity of the revealed preference model, an alternative approach was developed by Fischhoff, Slovic and others [29]: their expressed preference model is embedded in the psychometric paradigm of risk perception. The model recommends considering individuals' decision frames - the extent of knowledge they have about the risk and their ability to utilise this knowledge optimally; the validity of past conduct and experience as an indicator of present preferences and familiarity with risk exposure; the alternatives of which they are aware and can undertake to be controllable over the risk; and the artificiality of risk source (with respect to nature, history and justifiability of risk) [30, 31]. The expressed preference model is justified by the subjectivity of safety assessment [32], which posits that even quite reasonable individuals may intuitively or heuristically judge activities with relatively low levels of risks to be unacceptably unsafe for them.

A compromise between the revealed and expressed preference approaches is the implied preferences approach [33], ascertained through examination of (legal) institutions that society has previously set up with regard to risk. Gough [7] argues that the proponents of this approach do not view the balance between costs, risks and benefits as represented in law as an optimal balance, but think of it as society's best attempt to date. Thus, the concept of risk 
acceptance transcends what is seen and evaluated by individuals, to assess what stands beyond the political, social and spatial environment of risk-related actions and decisions $[6,27]$. In essence, this reveals why debates over risk acceptance are claimed to be based on the public's trust in responsible risk analysts, regulators and managers, rather than the actual estimates of a risk, especially when people lack knowledge about that risk itself.

Following from this, Raynor and Cantor suggest the adaption of the original question 'How safe is safe enough?' to 'How fair is safe enough?' [34]. The shift in defining safety has led to questions regarding whether the procedure by which collective consent is obtained for a course of action is acceptable to those who must bear its consequences [27]; whether the principle that will be used to apportion liabilities for an undesired consequence is acceptable to those affected; and whether the institutions that make the decisions that manage and regulate the technology are worthy of fiduciary trust ([34]:p.4). This may also evolve critical questions on the fairness of both risk and safety distributions among individuals in varying socio-economic circumstances. Fairly distributed risk is viewed as less risky and, therefore, more acceptable to individuals than unfairly distributed risks [35].

Next, a discussion is deliberated about the aforementioned factors in the realm of flood risk. This discussion will confer a deep review on the factors affecting the level of acceptable flood risk, from the viewpoint of individuals.

\section{FACTORS UNDERLYING OF FLOOD RISK PERCEPTION AND ACCEPTANCE IN THE CONTEXT OF FLOOD-PRONE LAND USE}

In the process of flood-prone land use change, individuals' decisions are influenced by their perception of the probabilities and consequences of actual risk $[8,9,36]$. In general terms, risk perception deals with an individual's interpretation or impression based on an understanding of a particular threat that may potentially cause loss of life or property [37]. Under this paradigm, flood risk perception is formed by the association between qualitative risk characteristics of awareness, worry and preparedness [38]. Building upon the associations between these characteristics, four different typologies can be categorised to describe individuals' psychophysical/cognitive states when they face a risk, respond to it and make decisions to determine its acceptability contextualised within the process of flood-prone land use [12, 39].

These typologies will now be discussed in relation to some explanations provided by past research that examined the persistence of people in areas subject to flood hazards ([8]: p.71 and [9]:p.135).

\subsection{Unawareness}

For individuals (floodplain occupants) who usually feel positive and optimistic and who thus are not unduly concerned, flood risk exposure may be deemed relatively acceptable. Risk acceptance in this case is not attributed to sufficient confidence in an individual's measures undertaken to avoid and/or reduce the risk, but mostly to their general unawareness of the presence of that risk at first place. Invisibility of flood risk (e.g., the absence of any visual clues that might have alerted individuals to the presence of a local flood risk [40]) and deficiencies in the provision of information on the risk that should be provided by those assumed have professional knowledge - - regulatory agencies, risk managers, real estate agents, insurers, financiers and so on - can adversely affect their awareness and estimates of the potential risk [18]. It follows that if they are unaware of their flood risk, they would not make 
fully informed decisions on the way in which they should respond to that risk and, equally importantly, the way in which they can safely invest and/or live in areas subject to floods.

\subsection{Unconcern/sense of security}

For individuals who usually feel safe and, therefore, would have no sense of worry, flood risk exposure may be deemed relatively acceptable. Their emotions would not change with the exposure to risk events and/or the provision of risk-related information. However, they are also insufficiently prepared as they are more willing to gamble - in the context of the infrequency of serious floods - that they themselves will not suffer losses during their persistence in areas subject to flood hazards [40]. Many such people would choose to accept the risks of investing and/or living in areas subject to floods.

\subsection{Irresponsibility/risk denial}

For individuals who experience a greater sense of worry and negative emotions, such as anxiety, about risks, flood risk exposure may be deemed relatively unacceptable. They show strong denial and resistance to the risk and, therefore, expect to avoid and/or reduce that risk. However, rather than being self-responsible when they are averse to being affected by any risk, they prefer to rely on others to ameliorate losses for them, for example through state compensation, insurance or other mechanisms. Some such individuals would accept the risk of investing/living in areas subject to floods.

\subsection{Controllability}

For individuals who characteristically believe that they have made sufficient preparations regarding the risk and thereby exhibit a strong sense of control over it, flood risk exposure may be deemed relatively unacceptable. They believe that they should be fully prepared and have undertaken, or are planning to undertake, all sufficient preventative measures to avoid/ reduce the loss. What distinguishes this typology is that, because they feel positive and optimistic, they prefer to consider flood protection from its beneficial perspective - usually measured in losses avoided. It follows that, because they are usually fully aware of their flood risk, they make fully informed decisions on the way in which they can safely invest and/or live in areas subject to floods.

Nevertheless, people's persistence in areas subject to flood hazard is not explained solely with respect to their perception of location-related risks: at least two more explanations could be added to the aforementioned list, according to Fordham ([8]:p.71), He ([10]:p.12) and James et al. ([16]:footnote 44).

\subsection{Benefit perception/ residential satisfaction}

Some floodplain occupants expect to bear a loss (risk taking) but see this outcome as an acceptable cost of enjoying the derived locational benefits 'risk compensation' [41]. As urban areas grow, both geographically and demographically, flood-prone areas have long been sought as sites for urban development because of the amenities they offer [42], or their resource potential as identified by Burby [1]. A large body of empirical research on the residential choice of hazardous environments has revealed that many floodplain residents were 
aware of the location-related risk and tolerated it to varying degrees because of the perceived location-based benefits $[10,11,16]$.

Location-based benefits, which have been viewed as essential elements of residential satisfaction on flood-prone environments choice, include [10]: natural amenities (such as scenic views, clean air and quiet surroundings, outdoor recreational opportunities, and other activities based on the location-embedded biophysical environment); neighbourhood social, economic and physical features (such as psychological bonds with a place, perceptions of privacy and safety at home, community cost of living, and other infrastructural and equipment settings, such as lighting of streets, crowding and noise level); and accessibility, preference and characteristics of housing ( such as size and age of houses, interior and proximal exterior environments, and other aspects of housing, for example, building quality and disrepair).

A flow diagram is provided in Fig. 1 to illustrate the relationships between residential satisfaction, responses to dissatisfaction, the importance of location-related benefits in the trade-off process with one's perception and acceptance of location-related risks. The diagram focuses on the trade-off process within which the level of worry links risk perception to the benefits of risk taking, as follows: theoretically, a higher level of worry reduces flood-prone residents' willingness to accept flood risk, which in turn hampers their intentions to reap the benefits from flood-prone land use, and increases their flood preparedness intentions. As a consequence, this process may eventually dissuade the user intentions to invest/live in an area subject to flood. Once the intensity of the dissatisfaction exceeds the threshold of tolerance, individuals may adopt some effective responses or behavioural adjustments to relieve their dissatisfactions [10]. There is, therefore, a circulating feedback mechanism between the responses to the element of residential satisfaction.

\subsection{Involuntariness}

Some floodplain occupants have little or no choice about where to live and must therefore stay. This explanation is a necessary counterbalance to the dominant decision's emphasis on

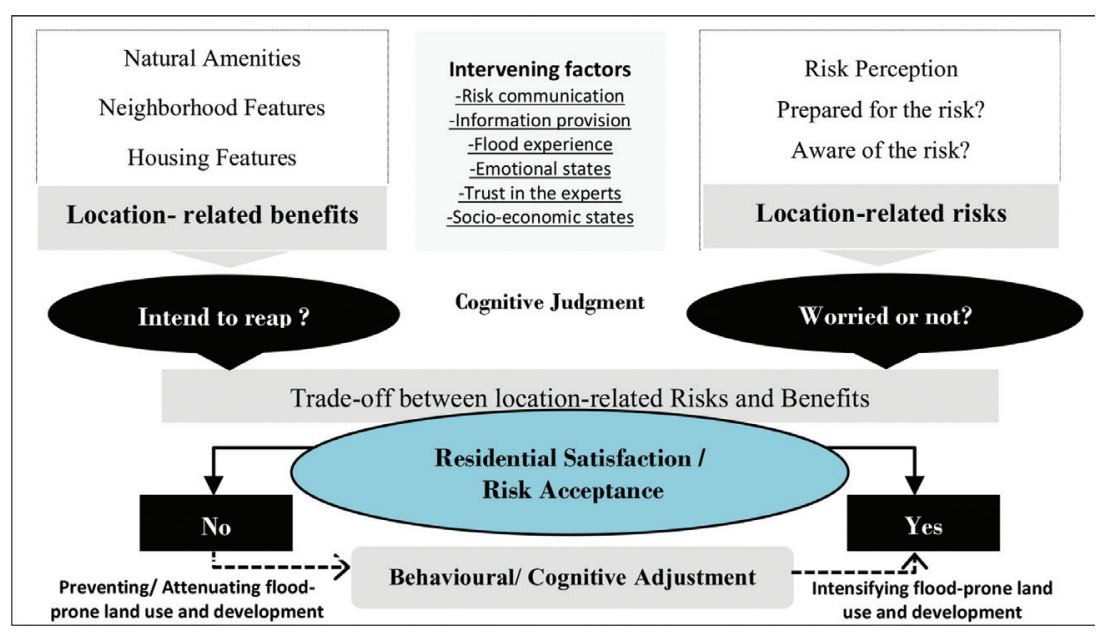

Figure 1: Trade-off between location-related risks and derived locational benefits. 
voluntary individual choice as elucidated by Starr [28]. In fact, most flood types - flash floods, riverine floods and storm tides - are predominantly classified as involuntary events, 'acts of God', caused by any natural hazard [15]. On the contrary, White and Haas [43]: claim that natural hazards have a strong component of voluntary risk when they result from interactions between human activities and destructive events ([43]: p.88). Thus, if a flood threatens an urban area with existing regulatory development constraints, the risk will be classified as voluntary. This enforces voluntariness preferences in making decisions relating to the process of flood-prone land-use change [18] - that extends over time, involves numerous decision points and actors and requires the balancing of multiple objectives, future scenarios, priorities and risk reduction strategies. The process of flood-prone land use usually begins with decisions made by landowners, within constraints imposed by law and regulations. Beginning with vacant land, the alternatives for them are not to develop, develop and sell, develop and occupy, or develop and lease. If the flood-prone land is already developed, the alternatives include whether to occupy the site 'as is' or further develop the site with or without accompanying actions to reduce and mitigate of the risk.

With respect to whether people voluntarily choose to live in a flood risk area, previous analyses reveal that in some cases, voluntariness in risk taking is at times less to do with choice and more to do with lack of choice (e.g., housing affordability or changing life circumstances such as age, health, poverty and access to jobs), the inevitability of natural disasters (that the natural world is unable to be controlled), and perceived development potential and economic growth [44, 45]. Further, the lack of choice, or the involuntariness situation, is essentially based on the assumption that people in modern and urbanised societies like Australia cannot invest or live wherever they like. This assumption ignores the whole land use planning and building code system, which regulates where people can and cannot build homes, and under what conditions. It also ignores the way in which almost all new housing projects are created-by market forces and large-scale private sector land development companies that have political influence and the capacity to negotiate favourable conditions and win legal battles ([44]: p.532).

However, understanding public perception of risk can defy involuntary risk, which is determined not by the public but by controlling agents external to them. This requires policymakers to deepen their understanding of how flood risk is constituted by those who may be simultaneously 'risk takers' and 'at risk'. This understanding is of obvious importance where there is a decision to be made with respect to risk acceptance, as well as on the trustworthiness, efficacy and fairness of the associated regulatory development constraints set by experts and policymakers $[8,17,18]$ - such as the 100-year flood regulatory threshold $[5,46]$.

In fact, the use of the 100-year flood as a regulatory constraint for the boundaries of acceptable flood risk, which informs the determination of minimum residential floor levels, has been widely criticised [47]. When it is represented in technical language, the '100-year ARI flood' (where ARI is average recurrence interval) term might be filtered differently by the general public than by those who originally produced and applied its content for residential planning purposes [48]. According to Bill and Tobin [47], this may be the initial goal behind the adoption of the 100-year flood standard in the United States: not effective communication of risk or risk policy, but efficient administration and implementation to minimise potential loss of life and property and maximise the economic benefits to be derived from floodplain development. ([47]: p.303). In light of this, Handemr [44] has indicated that such standards should be seen as the 'tolerated risk' because rarely is there genuine public debate and 'active' 


\section{Flood Risk Management and Response}

acceptance, as opposed to passively putting up with risk for the local population living in areas prone to flooding [44]. Here emerge the critical issues of the public's exclusion and lack of trust, and the ineffectiveness of risk communication efforts and strategies, which in turn may hamper the ability of decision makers to ensure that community and urban development occurs in a resilient manner.

To deal with such issues in a way that enhances public trust in the political environment, decision makers must accept and involve the judgement of those who actually face the complexity of making a place-based choice in consideration of their own sense of benefits, costs and land use constraints. From this perspective, 'active acceptance' is seen as a prerequisite for successful decisions enabling individuals to be active negotiators of risk [49] and therefore to ultimately settle fairly and with a strong commitment to their safety and well-being. White and Haas [43] in this respect claim that 'aggregated individual preferences towards risk must be adopted to set the threshold acceptable to the general public' ([43]:p.89). This has important social equity implications with respect to the formulation of flood acceptance levels depending on the actual local conditions (e.g. home values and socio-economic circumstances) and the wishes of local communities. To conclude, decisions made on behalf of the community are more likely to be accepted if there has been open communication and consultation with the affected communities, so that the risk is readily understood.

However, while the involvement of individuals and agencies with regard to both technical and socio-political imperatives can lead to consensus on what can be controversial issues around flood risk perception, acceptance and floodplain management [19], engaging 'the community' can be challenging due to several barriers, such as [50-52]:

(1) Low prioritisation and acknowledgement of natural hazards compared to other immediate, day-to-day and pressing concerns such as housing affordability, unemployment and crime rate.

(2) Resource constraints that can lead to self-perpetuating short-term technical fixes rather than long-term integrated and consultative approaches to addressing problems.

(3) Lack of institutional autonomy or political will.

(4) Issues concerning stakeholder identification and knowledge levels. Thus, this is actually a dilemma over 'whose' perceptions of risk, interests in land-use etc. should be considered (whether previous, current or future residents). It is also over the awareness of the hazard, especially with the lack of both easily accessible and understandable information. Problems associated with the provision of information include impacts on land values and insurance prices, intellectual property and liability for incorrect information.

(5) Well-intentioned higher-level policies and practice (such as levee and other flood control structures) that take the risk and burden off individual property owners, communities and local authorities, discouraging risk-averse behaviour including public consultation.

(6) The uncertainty that surrounds flooding and the unique characteristics of each flood event ([53]:143).

\section{CONCLUSION}

Bridging the divide between those who manage disaster risk and those who bear the consequences is key to realising the promise of land-use planning to reduce disaster risk and build sustainable, hazard-resilient communities in flood-prone areas. In light of this, it is important to note that the heterogeneity of populations at risk adds to the complexity of this issue. For example, some research in this respect has revealed that more deprived populations, and 
those belonging to lower social classes, are the most likely to be living in zones at risk of flooding $[40,54]$. Hence, we suggest that personalised risk assessment, based on qualitative risk characteristics, socio-economic circumstances, experience and feelings, is more likely to motivate risk acceptance and behavioural action than simply providing technical information about risks and consequences - supporting the findings of $[55,56]$.

In the absence of an integrated, holistic view that brings together all the underlying factors of individuals' willingness to accept flood risk in the context of flood-prone land use, the need for this paper is evident. Hence, the paper attempts to explicitly cover this issue by shedding more light on the articulation of six typologies that describe individuals' psychophysical/cognitive states when they face the risk, respond to it and determine its acceptability contextualised within the process of flood-prone land use change. This would provide valuable insights into how the level of acceptable risk (based on a subjective risk assessment) can be altered by the way in which the location-related risks are perceived relative to the location-related benefits derived from flood-prone land use; by the way in which the related risk information and policy are interpreted and evaluated in terms of their efficacy, voluntariness, trustworthiness and degree of fairness; and by the way in which intervening factors including socio-economic circumstances vary to provide a holistic picture of individuals' systems.

To date, there has been little or no advancement in this area, with research highlighting such inhibitive issues as the way in which the acceptable risk levels are (actively) conceived by the public and then incorporated into acceptable risk standards and floodplain land use policy. Broadening the scope of future research is vital.

\section{REFERENCES}

[1] Burby, R.J., Cooperating with Nature: Confronting Natural Hazards with Land-Use Planning for Sustainable Communities, Joseph Henry Press, 1998.

[2] Godschalk, D.R., Brody, S. \& Burby, R., Public participation in natural hazard mitigation policy formation: challenges for comprehensive planning. Journal of Environmental Planning and Management, 46(5), pp. 733-754, 2003. http://dx.doi.org/10.1080/0964056032000138463

[3] Berke, P. \& Smith, G., Hazard mitigation, planning, and disaster resiliency: Challenges and strategic choices for the 21st century. Building Safer Communities. Risk Governance, Spatial Planning and Responses to Natural Hazards, pp. 1-18, 2009.

[4] Burby, R.J., Beatley, T., Berke, P.R., Deyle, R.E., French, S.P., Godschalk, D.R., et al., Unleashing the power of planning to create disaster-resistant communities. Journal of the American Planning Association, 65(3): pp. 247-258, 1999.

http://dx.doi.org/10.1080/01944369908976055

[5] Godber, A.M., Urban Floodplain Land-use-Acceptable Hazard? A Case Study of Flood Risk Perception on the Guragunbah Floodplain (Nerang River System), Gold Coast, 2002.

[6] Kasperson, R.E., Acceptability of human risk. Environmental Health Perspectives, 52, pp. 15-20, 1983. http://dx.doi.org/10.1289/ehp.835215

[7] Gough, J.D., A Review of the Literature Pertaining to 'Perceived' Risk and 'Acceptable' Risk and the Methods used to Estimate them, Lincoln University \& University of Canterbury. Centre for Resource Management, 1990. 
72 Flood Risk Management and Response

[8] Fordham, M.H., Choice and Constraint in Flood Hazard Mitigation: the Environmental Attitudes of Floodplain Residents and Engineers, Middlesex University, 1992.

[9] Kates, R.W., Hazard and Choice Perception in Flood Plain Management, University of Chicago: Chicago, p. 157, 1962.

[10] He, X., Residential Satisfaction with Home Location: Examination of the Relationship Between Location-Embedded Benefits and Risk Perception, Texas State University-San Marcos, 2009.

[11] Vogt, M., Willis, K. \& Vince, J., Weighing Up the Risks-the Decision to Purchase Housing on a Flood Plain, 2008.

[12] Raaijmakers, R., Krywkow, J. \& van der Veen, A., Flood risk perceptions and spatial multi-criteria analysis: an exploratory research for hazard mitigation. Natural Hazards, 46(3), pp. 307-322, 2008. http://dx.doi.org/10.1007/s11069-007-9189-z

[13] Zhai, G. \& Ikeda, S., Empirical analysis of Japanese flood risk acceptability within multi-risk context. Natural Hazards and Earth System Science, 8(5), pp. 1049-1066, 2008 . http://dx.doi.org/10.5194/nhess-8-1049-2008

[14] Zhai, G. \& Ikeda, S., Flood risk acceptability and economic value of evacuation. Risk Analysis, 26(3), pp. 683-694, 2006. http://dx.doi.org/10.1111/j.1539-6924.2006.00771.x

[15] White, G.F., Human Adjustment to Floods, 1945.

[16] James, L.D., Laurent, E.A. \& Hill, D.W., The Flood Plain as a Residential Choice: Resident Attitudes and Perception and Their Implications to Flood Plain Management, Environment Resources Center, Georgia Institute of Technology: Atlanta, GA, 1971.

[17] McPherson, H.J. \& Saarinen, T.F., Flood plain dwellers' perception of the flood hazard in Tucson, Arizona. The Annals of Regional Science, 11(2), pp. 25-40, 1977. http://dx.doi.org/10.1007/BF01287852

[18] Bollens, S.A., Kaiser, E.J. \& Burby, R.J., Evaluating the effects of local floodplain management policies on property owner behavior. Environmental Management, 12(3), pp. 311-325, 1988. http://dx.doi.org/10.1007/BF01867522

[19] nunes Correia, F., Fordham, M., Saravia, M.A.G. \& Bernardo, F., Flood hazard assessment and management: interface with the public. Water Resources Management, 12(3), pp. 209-227, 1998. http://dx.doi.org/10.1023/A:1008092302962

[20] Kates, R.W. \& White,G.F., Flood hazard evaluation. Papers on Flood Problems: Department of Geography Research Paper, 70, pp. 135-147, 1961.

[21] Vrijling, J., Probabilistic design of water defense systems in The Netherlands. Reliability Engineering \& System Safety, 74(3), pp. 337-344, 2001. http://dx.doi.org/10.1016/S0951-8320(01)00082-5

[22] Vrijling, J.K., Van Gelder, P.H., Goossens, L.H.J., Voortman, H.G. \& Pandey, M.D., A framework for risk criteria for critical infrastructures: fundamentals and case studies in the Netherlands. Journal of Risk Research, 7(6), pp. 569-579, 2004. http://dx.doi.org/10.1080/1366987032000081178

[23] Molino, S. \& Karwaj, A., Do we understand what is an acceptable flood risk? the people of Australia have their say. In Proceedings of the 52nd Annual Floodplain Management Authorities Conference, 2012. 
[24] Zhai, G., Public preference and willingness to pay for flood risk reduction. A better integrated management of disaster risks: toward resilient society to emerging disaster risks in mega-cities, TERRAPUB: Tokyo, pp. 1-21, 2006.

[25] Fischhoff, B., Acceptable risk: a conceptual proposal. Risk, 5, p. 1, 1994.

[26] Vrijling, J., Van Hengel, W. \& Houben, R., A framework for risk evaluation. Journal of Hazardous Materials, 43(3), pp. 245-261, 1995. http://dx.doi.org/10.1016/0304-3894(95)91197-V

[27] Bell, R., Glade, T. \& Danscheid, M., Risks in defining acceptable risk levels. Landslide Risk Management, Supplementary, 400, pp. 38-44, 2005.

[28] Starr, C., Social benefit versus technological risk. Readings in Risk, pp. 183-194, 1969.

[29] Slovic, P., Fischhoff, B. \& Lichtenstein, S., Rating the risks. Environment: Science and Policy for Sustainable Development, 21(3), pp. 14-39, 1979. http://dx.doi.org/10.1080/00139157.1979.9933091

[30] Slovic, P., Perception of risk. Science, 236(4799), pp. 280-285, 1987. http://dx.doi.org/10.1126/science. 3563507

[31] Fischhoff, B., Slovic, P. \& Lichtenstein, S., Weighing the risks: risks: benefits which risks are acceptable? Environment: Science and Policy for Sustainable Development, 21(4), pp. 17-38, 1979. http://dx.doi.org/10.1080/00139157.1979.9929722

[32] Macpherson, J.A., Safety, risk acceptability, and morality. Science and Engineering Ethics, 14(3), pp. 377-390, 2008. http://dx.doi.org/10.1007/s11948-008-9058-5

[33] Rowe, W.D., Risk assessment approaches and methods. Society, Technology and Risk Assessment, p. 343, 1980.

[34] Rayner, S. \& Cantor, R., How fair is safe enough? the cultural approach to societal technology choice1. Risk Analysis, 7(1), pp. 3-9, 1987. http://dx.doi.org/10.1111/j.1539-6924.1987.tb00963.x

[35] Covello, V. \& Sandman, P.M., Risk communication: evolution and revolution. Solutions to an Environment in Peril, pp. 164-178, 2001.

[36] Kates, R.W., Perceptual regions and regional perception in flood plain management. Papers in Regional Science, 11(1), pp. 217-227, 1963. http://dx.doi.org/10.1111/j.1435-5597.1963.tb01899.x

[37] Bradford, R., O’Sullivan, J.J., van der Craats, I.M., Krywkow, J., Rotko, P. \& Aaltonen,J., et al., Risk perception-issues for flood management in Europe. Natural Hazards and Earth System Science, 12(7), pp. 2299-2309, 2012. http://dx.doi.org/10.5194/nhess-12-2299-2012

[38] Scolobig, A., De Marchi, B. \& Borga, M., The missing link between flood risk awareness and preparedness: findings from case studies in an Alpine Region. Natural Hazards, 63(2), pp. 499-520, 2012. http://dx.doi.org/10.1007/s11069-012-0161-1

[39] Meng, B., Liu, M., Yan Liufu, H. \& Wang, W., Risk perceptions combining spatial multi-criteria analysis in land-use type of Huainan city. Safety Science, 51(1), pp. 361373, 2013. http://dx.doi.org/10.1016/j.ssci.2012.08.010

[40] Burningham, K., Fielding, J. \& Thrush, D., 'It'll never happen to me': understanding public awareness of local flood risk. Disasters, 32(2), pp. 216-238, 2008. http://dx.doi.org/10.1111/j.1467-7717.2007.01036.x 
74 Flood Risk Management and Response

[41] Schmidt, M., Investigating Risk Perception: a Short Introduction, Vienna, Austria, 2004.

[42] Montz, B., The generation of flood hazards and disasters by urban development of floodplains. Floods,1, pp. 116-127, 2000.

[43] White, G.F. \& Haas, J.E., Assessment of Research on Natural Hazards, Mit Press, 1975.

[44] Handmer, J., Risk creation, bearing and sharing on Australian floodplains. International Journal of Water Resources Development, 24(4), pp. 527-540, 2008. http://dx.doi.org/10.1080/07900620801921439

[45] Kaiser, E.J., Burby, R.J., Bollens, S.A. \& Holway, J.M., Private sector land market decision agents as targets of floodplain policy. International Journal of Mass Emergencies and Disasters, 5(3), pp. 311-335, 1987.

[46] Ludy, J. \& Kondolf, G.M., Flood risk perception in lands "protected" by 100-year levees. Natural Hazards, 61(2), pp. 829-842, 2012. http://dx.doi.org/10.1007/s11069-011-0072-6

[47] Bell, H.M. \& Tobin, G.A., Efficient and effective? The 100-year flood in the communication and perception of flood risk. Environmental Hazards, 7(4), pp. 302-311, 2007. http://dx.doi.org/10.1016/j.envhaz.2007.08.004

[48] Smith, D., Problems, issues and opportunities. Floods, 1, p. 254, 2000.

[49] Lupton, D., 1 Sociology and risk. Beyond the risk society: Critical reflections on risk and human security, p. 11, 2006.

[50] Godber, A.M., Hastings, P.A. \& Childs, I.R., Local government views on addressing flood risk management on the gold coast. The Australian Journal of Emergency Management, 21(3), pp. 34-40, 2006.

[51] Burby, R., Policies for sustainable land use. Cooperating with Nature: Confronting Natural Hazards with Land-Use Planning for Sustainable Communities, The National Academies Press: Washington, pp. 263-291, 1998.

[52] May, P.J. \& Deyle, R.E., Governing land use in hazardous areas with a patchwork system. Cooperating with nature: Confronting natural hazards with land-use planning for sustainable communities, pp. 57-82, 1998.

[53] Deyle, R.E., French, S.P., Olshansky, R.B. \& Paterson, R.G., Hazard assessment: the factual basis for planning and mitigation. Cooperating with Nature: Confronting Natural Hazards and Land use Planning for Sustainable Communities, pp. 119-166, 1998.

[54] Fielding, J. \& Burningham, K., Environmental inequality and flood hazard. Local Environment, 10(4), pp. 379-395, 2005. http://dx.doi.org/10.1080/13549830500160875

[55] Rocha, J.S. \& Correia, F.N., Public perception of flood risk and flood defence policies. In Defence from Floods and Floodplain Management, Springer: Netherlands, pp. 457-477, 1995.

[56] Fordham, M., Participatory planning for flood mitigation: models and approaches. Australian Journal of Emergency Management, 13(4), pp. 27-34, 1999. 